\title{
Acetylcholine Signaling Genes are Required for Cocaine-Stimulated Egg Laying in Caenorhabditis elegans
}

Soren Emerson ${ }^{1}$, Megan Hay²*, Mark Smith ${ }^{1,3}$, Ricky Granger ${ }^{2}$, David Blauch ${ }^{4}$, Nicole Snyder ${ }^{4}$, and Rachid El Bejjani ${ }^{1,2} \dagger$

Departments of ${ }^{1}$ Neuroscience Interdisciplinary Program, ${ }^{2}$ Biology, ${ }^{3}$ Psychology, and ${ }^{4}$ Chemistry, Davidson College, Davidson, North Carolina 28035

${ }^{*}$ Radboud University. Houtlaan 4, 6525 XZ Nijmegen, Netherlands 
Running title: Acetylcholine-dependent cocaine activity

Keywords: Cocaine, Caenorhabditis elegans, egg laying, acetylcholine, serotonin, dopamine, tyramine, octopamine, acetylcholinesterase, L-amino acid decarboxylase, tyrosine beta-hydroxylase, tyrosine decarboxylase, nicotinic acetylcholine receptor, muscarinic acetylcholine receptor, vesicular acetylcholine transporter, $\mathrm{Gq}$ alpha subunit

†Corresponding author: Dr. Rachid El Bejjani, raelbejiani@davidson.edu, Davidson College, PO BOX 7118, Davidson, North Carolina 28035 
The toxicity and addictive liability associated with cocaine abuse are well known. However, its mode of action is not completely understood, and effective pharmacotherapeutic interventions remain elusive. The cholinergic effects of cocaine on acetylcholine receptors, synthetic enzymes, and degradative enzymes have been the focus of relatively little empirical investigation. Due to its genetic tractability and anatomical simplicity, the egg laying circuit of the hermaphroditic nematode, Caenorhabditis elegans, is a powerful model system to precisely examine the genetic and molecular targets of cocaine in vivo. Here, we report a novel cocaine-induced behavioral phenotype in Caenorhabditis elegans, cocaine-stimulated egg laying. In addition, we present the results of an in vivo candidate suppression screen of synthetic enzymes, receptors, degradative enzymes, and downstream components of the intracellular signaling cascades of the main neurotransmitter systems that control Caenorhabditis elegans egg laying. Our results show that cocaine-stimulated egg laying is dependent on acetylcholine synthesis and synaptic release, functional nicotinic acetylcholine receptors, and the Caenorhabditis elegans acetylcholinesterases. 


\section{INTRODUCTION}

Cocaine abuse is estimated to account for 900,000 cases of substance use disorder and over 14,000 overdose deaths in the United States each year (Lipari and Van Horn 2013; Hedegaard et al. 2020). Despite the impact of cocaine abuse on public health, there are no FDA-approved pharmacotherapeutic interventions for either the addictive liability or toxicity associated with cocaine abuse (Kampman 2019). A major impediment to the development of effective pharmacological interventions is the nonspecificity of the drug, as pharmacodynamic interventions designed to block the canonical monoamine neurotransmitters implicated in the mode of action of cocaine (dopamine (DA), serotonin (5-HT), and norepinephrine) have demonstrated limited efficacy in clinical trials (Pitts and Marwah 1989; Czoty et al. 2016). Elucidation of the full range of neurotransmitter systems and molecular effectors involved in the mode of action of cocaine could inform the development of novel pharmacotherapies.

Cholinergic signaling influences multiple processes underlying reward and dependence in the mammalian brain, including learning, attention, and motivation (Hasselmo 2006; Sofuoglu and Mooney 2009; Klinkenberg et al. 2011). In addition, behavioral and physiological research demonstrates an important role for acetylcholine (ACh) in the pathology of cocaine use disorder (Williams and Adinoff 2008). However, the cholinergic mechanisms of cocaine have not been fully investigated.

The Caenorhabditis elegans egg laying circuit has served as a tractable genetic and molecular model for the mechanistic underpinnings of various neurotransmitters, including ACh and the biogenic amines 5-HT, DA, octopamine (Oct), and tyramine (Tyr) (Schafer 2005; Chase 2007). The circuit consists of two hermaphrodite-specific motor 
neurons (HSNs) and six ventral type C motor neurons (VCs) that innervate eight vulval muscles (Schafer 2006). ACh plays a crucial and complex role in regulating the egg laying behavior of C. elegans (Rand 2007). The VCs, which are the primary cholinergic neurons in the egg laying circuit, innervate both the vulval muscles and the HSNs (White et al. 1986). Although typically regarded as serotonergic motor neurons, the HSNs have also been reported to function as cholinergic motor neurons in the egg laying circuit (Duerr et al. 2001; Pereira et al. 2015). ACh elicits excitatory and inhibitory effects on egg laying. The excitatory effect of ACh on egg laying is mediated by binding to nicotinic ACh receptors (nAChRs) on the vulval muscles inducing contraction and egg laying (Kim et al. 2001). Cholinergic inhibition of egg laying may result from binding of ACh to muscarinic ACh receptors (mAChRs) expressed in the egg laying circuit (Bany et al. 2003; Fernandez et al. 2020).

Here, we characterize a novel cocaine-induced behavioral phenotype in $C$. elegans, cocaine-stimulated egg laying, and present pharmacological and genetic evidence for the dependence of this behavioral phenotype on ACh, nAChRs, and acetylcholinesterases (AChEs). We show that the excitatory effect of cocaine on egg laying in C. elegans depends on genes involved in nicotinic cholinergic neurotransmission but not on the majority of genes encoding the molecular components of the other neurotransmitter systems expressed in the egg laying circuit. Together, our results provide a background for future investigation utilizing the $C$. elegans egg laying circuit to elucidate the cholinergic effects of cocaine. 


\section{MATERIALS AND METHODS}

\section{Nematode strains}

The wildtype (WT) strain was Bristol N2. Animals were maintained on standard nematode growth media agar plates spread with Escherichia coli as a source of food (Stiernagle 2006). Temperature was controlled at $20^{\circ} \mathrm{C}$. Table S3 contains a complete list of all of the mutant $C$. elegans strains used in this study.

\section{Egg laying assays and statistical analysis}

Egg laying assays in liquid media were performed according to a protocol by Moresco and Koelle (Hart 2006). For each experiment, an aqueous stock solution of $147.15 \mathrm{mM}$ cocaine hydrochloride $(50.000 \mathrm{mg} / \mathrm{mL})$ was diluted to the desired treatment concentration in M9 buffer solution with an equal volume of $147.15 \mathrm{mM}$ aqueous sucrose solution $(50.369 \mathrm{mg} / \mathrm{mL})$ diluted in $\mathrm{M} 9$ buffer solution in each of the control conditions. Late stage L4 hermaphrodites of the respective strains were picked $\sim 24 \mathrm{hrs}$ before assaying and continued to be cultured on agar plates with an OP50 lawn at $20^{\circ} \mathrm{C}$. Ten day one adult hermaphrodites were isolated into single wells on a 96-well plate containing $35 \mu \mathrm{l}$ experimental or equimolar control solutions for each replicate. After $1 \mathrm{hr}$, each well was examined, and the number of eggs laid by each animal was recorded.

For all liquid media egg laying assays, the investigators were blind to both the identity of the treatment and the genotype. Each experiment included 10 animals per experimental or control group, and each experiment was independently repeated five times. Seventeen total worms ruptured during experimental analysis. In these rare 
cases, the non-ruptured worms in the replicate were used to score the egg laying response.

For the analysis of the mean egg laying response, the mean number of eggs laid by each of the five replicate treatment groups was treated as a single data point. For the analysis of fraction responding, defined as the fraction of animals laying greater than or equal to one egg, the fraction responding of each of the five replicate treatment groups was treated as a single data point. Statistical analysis of the mean egg laying response and the fraction responding was performed using a Mann-Whitney U-test.

\section{Chemicals}

Aqueous cocaine hydrochloride was supplied by the National Institute on Drug Abuse (Research Triangle Institute, Research Triangle Park, NC, USA).

\section{Data Availability Statement}

All mutant strains examined in this study are available to order from the Caenorhabditis Genetics Center. The authors affirm that all data necessary for confirming the conclusions of this article are represented fully within the article and its tables and figures.

\section{RESULTS}

High concentrations of cocaine overcome the inhibition of egg laying in

\section{hypertonic liquid media}

In an effort to add to the current cocaine abuse models available in $C$. elegans, we quantified any differences in egg laying in $C$. elegans treated with cocaine by assaying the mean egg laying response over a time period of $1 \mathrm{hr}$ in hypertonic liquid 
media, a well-established method previously used to investigate the stimulation of egg laying by pharmacological agents (Horvitz et al. 1982; Trent et al. 1983; Desai and Horvitz 1989; Schafer and Kenyon 1995; Weinshenker et al. 1995; Jayanthi et al. 1998; Dempsey et al. 2005; Ward et al. 2009; Engleman et al. 2016; Engleman et al. 2018; Hart 2006). We tested the mean egg laying response of $C$. elegans to a series of increasing concentrations of cocaine (0 mM, $15.625 \mathrm{mM}, 31.25 \mathrm{mM}$, and $62.5 \mathrm{mM})$ in liquid media for $1 \mathrm{hr}$ (Fig. 1A). We show that treatment of WT C. elegans with $62.5 \mathrm{mM}$ cocaine significantly stimulates egg laying compared to equimolar sucrose control [WT, $62.5 \mathrm{mM}$ cocaine mean $=6.1 \pm 2.2 ; \mathrm{WT}, 62.5 \mathrm{mM}$ sucrose control mean $=0.34 \pm 0.56 ; p<$ 0.0001, N = 83 replicates (10 animals/replicate)] (Fig. 1B).

We used a $62.5 \mathrm{mM}$ cocaine treatment and $62.5 \mathrm{mM}$ sucrose control in all mutant analyses described in this paper. Interestingly, the concertation of cocaine necessary to robustly stimulate $C$. elegans egg laying behavior is greater than the concentrations of cocaine previously shown to modulate C. elegans locomotion by Ward et al (2009).

\section{ACh is the only neurotransmitter required for the stimulation of egg laying by cocaine in hypertonic liquid media}

To begin investigating the neurobiological mechanism of cocaine-stimulated egg laying, we screened the egg laying response of individual mutants with defects in the synthetic enzymes for each of the neurotransmitters previously implicated in egg laying

(Fig. 2A) (Schafer 2005). Interestingly, a reduction of function allele of cha-1(p1152), which encodes choline acetyltransferase (ChAT) necessary for ACh synthesis, suppresses egg laying in response to cocaine compared to WT [cha-1(p1152), cocaine 
mean $=0.5 \pm 0.3 ; \mathrm{WT}$, cocaine mean $=4.8 \pm 1.8 ; p=0.0079, \mathrm{~N}=5$ replicates $(10$ animals/replicate)] (Fig. 2B) (Rand and Russell 1984; Rand and Russell 1985).

5-HT plays a well described excitatory role in the egg laying circuit, and 5-HT signaling is one of the canonical targets of cocaine in mammals (Higgins and Fletcher 2003; Schafer 2006; Müller et al. 2007; Schafer 2005; Chase 2007). Surprisingly, a putative null allele of the $C$. elegans tryptophan hydroxylase (TPH), the 5-HT synthetic enzyme, did not suppress cocaine-stimulated egg laying compared to WT [tph$1(m g 280)$, cocaine mean $=5.2 \pm 1.8 ; \mathrm{WT}$, cocaine mean $=7.1 \pm 2.2 ; p=0.095, \mathrm{~N}=5$ replicates (10 animals/replicate)] (Fig. 2C) (Sze et al. 2000). These results suggest that 5-HT, one of the main modulators of egg laying behavior and a canonical cocaine effector in mammalian systems, is not a primary target of cocaine in this model system.

Additionally, putative null mutants for aromatic L-amino acid decarboxylase (AADC)/bas-1(ad446), which encodes a 5-HT and DA synthetic enzyme, tyrosine betahydroxylase $(\mathrm{TBH}) / t b h-1(n 3247)$, which encodes an Oct synthetic enzyme, and tyrosine decarboxylase (TDC)/tdc-1(n3419), which encodes a Tyr and Oct synthetic enzyme, do not exhibit a significant difference in the egg laying response to cocaine compared to WT, suggesting that neither DA, Tyr, nor Oct are necessary for cocaine-stimulated egg laying (Fig. 2D-F) (Hare and Loer 2004; Alkema et al. 2005).

\section{Cocaine-stimulated egg laying requires genes involved presynaptic ACh} signaling

Suppression of the egg laying response to cocaine in reduction of function ChAT/cha-1(p1152) mutants suggests that presynaptic cholinergic neurotransmission is necessary for the egg laying response to the drug. To further examine this possibility, 
we assayed cocaine-stimulated egg laying in mutants with a reduction of function mutation in the vesicular ACh transporter (VAChT)/unc-17(e245) necessary for packaging of ACh within synaptic vesicles (Alfonso et al. 1993). We show that the egg laying response of VAChT/unc-17(e245) mutants is suppressed compared to WT [unc17(e245), cocaine mean $=0.5 \pm 0.1 ; \mathrm{WT}$, cocaine mean $=5.4 \pm 1.3 ; p=0.0079, \mathrm{~N}=5$ replicates (10 animals/replicate)] and that cocaine does not stimulate a significant increase in egg laying in VAChT/unc-17(e245) mutants compared to equimolar sucrose control $[u n c-17(e 245)$, cocaine mean $=0.5 \pm 0.1 ; u n c-17(e 245)$, sucrose control mean = $0.4 \pm 0.4 ; p=0.64, \mathrm{~N}=5$ replicates (10 animals/replicate)] (Fig. $3 \mathbf{A})$.

The $\mathrm{Ga}_{\mathrm{q}}$ ortholog encoded by egl-30 in C. elegans is required for $\mathrm{ACh}$ release from motor neurons, among other neuronal functions (Lackner et al. 1999). We show that mutants with a reduction of function mutation in $\mathrm{Ga}_{\mathrm{q}} / \mathrm{egl}-30$ (ad806) exhibit suppressed cocaine-stimulated egg laying compared to WT [egl-30(ad806), cocaine mean $=2.2 \pm 2.0 ; \mathrm{WT}$, cocaine mean $=5.9 \pm 0.8 ; p=0.016, \mathrm{~N}=5$ replicates $(10$ animals/replicate)] and that cocaine does not stimulate a significant increase in egg

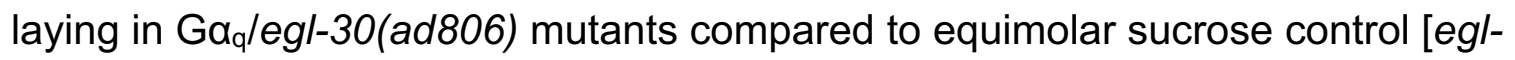
$30($ ad806), cocaine mean $=2.2 \pm 2.0 ;$ egl-30(ad806), sucrose control mean $=0.5 \pm 0.1$; $p=0.056, \mathbf{N}=5$ replicates (10 animals/replicate)] (Fig. 3B). Taken together, these results suggest that genes required for presynaptic ACh synthesis, packaging, and release are required for the egg laying response stimulated by cocaine in $C$. elegans. 


\section{Genes encoding nAChRs, but not mAChRs, are required for the egg laying response to cocaine}

To further examine the effect of cocaine on cholinergic signaling in the $C$. elegans egg laying circuit, we tested the egg laying response to cocaine in $n A C h R$ and mAChR mutants (Fig. 4 and 5) (Kim et al. 2001; Schafer 2006; Fernandez et al. 2020). Consistent with our finding that cholinergic neurotransmission is required for cocainestimulated egg laying, we show that the egg laying response to cocaine is significantly reduced compared to WT in unc-29(e1072) putative null mutants with defects in the beta subunit of nAChRs (CHRNB) [unc-29(e1072), cocaine mean = 1.5 \pm 0.97 ; WT, cocaine mean $=6.0 \pm 1.7 ; p=0.0079, \mathrm{~N}=5$ replicates $(10$ animals/replicate $)]$ (Fig. 4A) (Fleming et al. 1997). Similarly, we show that the egg laying response to cocaine of alpha subunit nAChR putative null mutants (CHRNA)/unc-38(e264) is suppressed compared to WT [unc-38(e264), cocaine mean $=3.8 \pm 1.2 ; \mathrm{WT}$, cocaine mean $=6.5 \pm 1.8$; $p=0.024, \mathbf{N}=5$ replicates (10 animals/replicate)] (Fig. 4C) (Richmond and Jorgensen 1999). These results suggest that $n A C h R s$ expressed on muscles, including the vulval muscles, are required for the molecular action of cocaine on C. elegans egg laying.

The response to cocaine of CHRNB/unc-29(e1072) mutants revealed an unexpected result. Specifically, although cocaine-stimulated egg laying is suppressed in CHRNB/unc-29(e1072) mutants compared to WT animals treated with cocaine, CHRNB/unc-29(e1072) mutants treated with cocaine show a significantly reduced egg laying response compared to that of CHRNB/unc-29(e1072) mutants treated with equimolar sucrose control [unc-29(e1072), cocaine mean = 1.5 \pm 0.97 ; unc-29(e1072) sucrose control mean $=4.4 \pm 0.8 ; p=0.0079, \mathrm{~N}=5$ replicates $(10$ animals $/$ replicate $)$ ] 
(Fig. 4A). To determine if this effect is generalizable for other alleles of CHRNB/unc-29, we repeated the experiment in a second CHRNB/unc-29(e403) allele. We show that, as observed for the CHRNB/unc-29(e1072) allele, CHRNB/unc-29(e403) mutants also exhibit a suppressed egg laying response to cocaine compared to WT [unc-29(e403), cocaine mean $=1.3 \pm 0.6 ; \mathrm{WT}$, cocaine mean $=4.6 \pm 1.2 ; p=0.0079, \mathrm{~N}=5$ replicates $(10$ animals/replicate)]. However, unlike CHRNB/unc-29(e1072), the egg laying response to cocaine of CHRNB/unc-29(e403) mutants does not significantly differ from the egg laying response in CHRNB/unc-29(e403) treated with sucrose control [unc-29(e403), cocaine mean $=1.3 \pm 0.6 ;$ unc-29(e403), sucrose control mean $=1.1 \pm 0.5 ; p=0.79, \mathrm{~N}=5$ replicates (10 animals/replicate)] (Fig. 4B). These results confirm the dependence of the egg laying response to cocaine on CHRNB/unc-29 and suggest that the unexpected, reduced egg laying response to cocaine compared to sucrose control in CHRNB/unc-29(e1072) mutants may be allele-specific or due to an unidentified background mutation in this strain.

In addition to nAChRs, the $C$. elegans egg laying circuit expresses several mAChRs (Fernandez et al. 2020). To determine if mAChRs are required for the molecular mechanism of cocaine-stimulated egg laying, we assayed the egg laying response to cocaine of putative null mutants for the three mAChRs encoded by gar1(ok755), gar-2(ok520), and gar-3(gk305) (Bany et al. 2003; Liu et al. 2007). We show all three mAChR mutants do not exhibit a significant difference in the egg laying response to cocaine compared to WT (Fig. 5A-C). 


\section{AChE-encoding genes are required for the egg laying response to cocaine}

AChEs catalyze the degradation of ACh at the synapse, decreasing cholinergic neurotransmission (Dvir et al. 2010). Biochemical analysis has revealed multiple genes encoding C. elegans AChEs, including ace-1, ace-2, ace-3, and ace-4 (Combes et al. 2001). The AChEs encoded by ace-1 and ace-2 are the major degradative enzymes of ACh whereas the AChE encoded by ace-3 accounts for a minor proportion of AChE activity, and the AChE encoded by ace- 4 is transcribed but does not result in a catalytically active protein (Johnson and Russell 1983; Kolson and Russell 1985; Arpagaus et al. 1998; Rand 2007). In order to explore all aspects of the relationship between cocaine and cholinergic signaling in the egg laying response, we tested the egg laying response to cocaine of ace-2(g72); ace-1(p1000) and ace-4 ace-3(dc2) putative null double mutants (Culotti et al. 1981; D. Combes et al. 2000). ace-2(g72); ace-1(p1000) double mutants exhibit a significant decrease in the egg laying response to cocaine compared to WT [ace-2(g72); ace-1(p1000), cocaine mean $=0.20 \pm 0.19 ; \mathrm{WT}$, cocaine mean $=5.2 \pm 2.6 ; p=0.0079, \mathrm{~N}=5$ replicates $(10$ animals/replicate $)]($ Fig. $6 \mathbf{A})$ whereas ace-4 ace-3(dc2) double mutants exhibit an egg laying response to cocaine that does not differ significantly compared to WT (Fig. 6B).

\section{Cocaine-stimulated egg laying is dependent on the HSNs but not 5-HT receptor genes}

The HSNs are the primary serotonergic motor neurons in the C. elegans egg laying circuit (Schafer 2006). In addition to their function as serotonergic motor neurons, the HSNs also function as cholinergic motor neurons (Duerr et al. 2001; Pereira et al. 2015). To further assess the role of the HSNs, 5-HT, and ACh in cocaine-stimulated egg 
laying, we quantified the egg laying response to cocaine in animals containing a semidominant allele of egl-1, shown to trigger HSN cell death (Conradt and Horvitz 1998). We show that egl-1(n487) mutants exhibit a slight but statistically significant difference in the egg laying response to cocaine compared to WT [egl-1(n487), cocaine mean = $7.2 \pm 1.2 ; \mathrm{WT}$, cocaine mean $=9.3 \pm 0.9 ; p=0.032, \mathrm{~N}=5$ replicates $(10$ animals/replicate)] (Fig. 7A). In addition, our data show that the HSNs contribute to cocaine-stimulated egg laying but that their presence is not necessary for the behavior. Specifically, cocaine stimulates a significant increase in egg laying compared to equimolar sucrose control in animals lacking the HSNs [egl-1(n487), cocaine mean = 7.2 $\pm 1.2 ;$ egl-1(n487), sucrose control mean $=1.2 \pm 0.9 ; p=0.0079, \mathrm{~N}=5$ replicates $(10$ animals/replicate)].

Our previous analysis of mutants with defects in cholinergic and serotonergic neurotransmission indicates that $\mathrm{ACh}$, but not $5-\mathrm{HT}$, is required for the stimulatory effects of cocaine on $C$. elegans egg laying behavior. To determine if cocaine acts on 5HT receptors in the egg laying circuit, we tested the egg laying response to cocaine in putative null mutants with defects in four metabotropic 5-HT receptors expressed in the C. elegans egg laying circuit. The genotypes tested include ser-5(ok3087), which encodes an excitatory $\mathrm{Ga}_{\mathrm{s}}$-coupled 5-HT receptor, ser-4(ok512), which encodes an inhibitory $\mathrm{Ga}_{\mathrm{o}}$-coupled 5-HT receptor, and a ser-7(tm1325) ser-1(ok345) double mutant, which encode an excitatory $\mathrm{Ga}_{\mathrm{q}}$-coupled 5-HT receptor and an excitatory $\mathrm{Ga}_{\mathrm{s}}$-coupled 5-HT receptor, respectively (Olde and McCombie 1997; Carnell et al. 2005; Hobson et al. 2006; Churgin et al. 2017). We show that ser-7(tm1325) ser-1(ok345) double mutants and ser-5(ok3087) mutants exhibit an egg laying response to cocaine that does 
not differ significantly compared to WT, suggesting that the excitatory post-synaptic effects of 5-HT are not required for cocaine-stimulated egg laying (Fig. 7B and D). Further, our data suggest that cocaine does not stimulate egg laying by blocking the inhibitory effects of ser-4(ok512) (Fig. 7C). Together, our data show that the egg laying response to cocaine depends on ACh receptors, but not 5-HT receptors, and suggest that suppression of the egg laying response to cocaine in egl-1(n487) mutants may result from a lack of presynaptic cholinergic neurotransmission by the HSN motor neurons.

Cocaine-stimulated egg laying is increased in 5-HT-gated chloride channel/mod-1 mutants and 5-HT reuptake transporter/mod-5 mutants

Cocaine induces a decrease in locomotion speed in $C$. elegans that is dependent on the gene mod-5, which encodes the C. elegans 5-HT reuptake transporter (SERT), and the gene mod-1, which encodes an inhibitory 5-HT-gated chloride channel (Ward et al. 2009). We tested the egg laying response to cocaine in 5-HT-gated chloride channel/mod-1(ok103) putative null mutants and SERT/mod-5(n3314) putative null mutants to examine the role of these genes in cocaine-stimulated egg laying (Ranganathan et al. 2000; Ranganathan et al. 2001). 5-HT-gated chloride channel/mod1(ok103) mutants exhibit a significant increase in the egg laying response to cocaine compared to WT [mod-1(ok103), cocaine mean = 18 \pm 3.2, WT, $62.5 \mathrm{mM}$ cocaine mean $=9.8 \pm 2.0 ; p=0.0079, \mathbf{N}=5$ replicates (10 animals/replicate)] (Fig. 8A). Similarly, SERT/mod-5(n3314) mutants exhibit a significant increase in the egg laying response to cocaine compared to WT $[\bmod -5(n 3314)$, cocaine mean $=14.8 \pm 1.3 ; \mathrm{WT}$, cocaine mean $=9.8 \pm 2.0 ; p=0.0079, \mathrm{~N}=5$ replicates (10 animals/replicate)] (Fig. 8B). The increased 
egg laying responses to cocaine in 5-HT-gated chloride channel/mod-1(ok103) mutants and SERT/mod-5(n3314) mutants suggest that the removal of 5-HT-gated chloride channel inhibition of egg laying or a global increase in 5-HT, respectively, may potentiate the egg laying response to cocaine.

\section{Cocaine-stimulated egg laying is weakly suppressed in DA reuptake transporter}

\section{mutants but not mutants with defects in other DA signaling genes}

The majority of mechanistic cocaine research has examined the drug's activity as a DA reuptake inhibitor (Nestler 2005). According to this mechanism, cocaine binds to and blocks the DA reuptake transporter (DAT), preventing removal of DA from the synapse and thereby potentiating dopaminergic neurotransmission. dat-1 encodes the C. elegans DAT, which has been shown to be sensitive to cocaine in heterologous systems (Jayanthi et al. 1998). To determine if DAT/dat-1 is required for the egg laying response to cocaine in $C$. elegans, we tested the egg laying response to cocaine in DAT/dat-1(ok157) putative null mutants (McDonald et al. 2007). DAT/dat-1(ok157) putative null mutants exhibit a weak but significant decrease in the egg laying response to cocaine compared to WT [dat-1(ok157), cocaine mean $=2.2 \pm 1.7$, WT, cocaine mean $=5.7 \pm 1.2 ; p=0.048, \mathrm{~N}=5$ replicates $(10$ animals/replicate)] (Fig. 9A). However, cocaine stimulates a significant increase in egg laying compared to equimolar sucrose control $[$ dat-1(ok157), cocaine mean $=2.2 \pm 1.7$; dat-1(ok157), sucrose control mean $=$ $0.2 \pm 0.3 ; p=0.0079, \mathrm{~N}=5$ replicates (10 animals/replicate) $]$.

Our analysis of the egg laying response to cocaine in mutants for the DA and 5HT synthetic enzyme, AADC/bas-1(ad446) (Fig. 1D), suggests that DA is not required for the egg laying response to cocaine. To further examine the role that DA plays in 
cocaine-stimulated egg laying, we tested the egg laying response to cocaine in a series of additional mutants with defects in DA signaling genes. The genotypes tested include putative null alleles of dop-2(vs105), which encodes a $\mathrm{Ga}_{\mathrm{o}}$-coupled DA receptor, dop3(vs106), which encodes a Ga -coupled DA receptor, dop-4(ok1321), which encodes a Gas-coupled DA receptor, and cat-2(e1112), which encodes the DA synthetic enzyme tyrosine hydroxylase (TH) (Lints and Emmons 1999; Chase et al. 2004; Cao and Aballay 2016; Fernandez et al. 2020). Consistent with our analysis of the egg laying response to cocaine in AADC/bas-1(ad446) mutants, neither $\mathrm{TH} /$ cat-2(e1112) mutants nor single mutants for the three genes encoding DA receptors expressed in the neurons and muscles that control C. elegans egg laying (dop-2(vs105), dop-3(vs106), and dop4(ok1321)) exhibit a significant difference in the egg laying response to cocaine compared to WT (Fig. 9B-E). Together, these data suggest that DA is not a primary target of cocaine in this model system.

\section{Fraction of WT, cholinergic mutant, and monoamine mutant $C$. elegans that exhibit an egg laying response to cocaine}

As is standard in the analysis of $C$. elegans egg laying behavior in response to pharmacological agents, we assayed the mean number of eggs laid in response to treatment by each of the genetic backgrounds tested compared to WT (Trent et al. 1983; Desai and Horvitz 1989; Schafer and Kenyon 1995; Weinshenker et al. 1995; Hart 2006). One limitation of comparing the mean eggs laid, however, is that it potentially obscures how the egg laying response to cocaine differs across the population of animals tested. To address this, we reanalyzed our data and calculated the fraction of wild type animals laying at least one egg in response to treatment with 
cocaine in hypertonic media for $1 \mathrm{hr}$ (Fig. 10A and B). We show that cocaine stimulates an egg laying response in $85 \pm 15 \%$ of WT animals tested whereas only $14 \pm 16 \%$ of WT animals treated with equimolar sucrose control lay at least one egg $[p<0.0001, \mathrm{~N}=83$ replicates (10 animals/replicate)] (Fig. 10B).

We also reanalyzed the fraction responding to cocaine in all mutant strains tested compared to WT. The fraction of animals that lay at least one egg mostly followed the same pattern observed when analyzing the mean number of eggs laid in $1 \mathrm{hr}$ (Table. S1 and S2).

\section{DISCUSSION}

Cocaine may modulate endogenous cholinergic neurotransmission to stimulate

\section{C. elegans egg laying}

In the present study, we show that the mean egg laying response to cocaine in C. elegans is suppressed in mutants with defects in presynaptic cholinergic neurotransmission, postsynaptic defects in nAChRs, and defects in the C. elegans AChEs. Together, these results suggest that cocaine may modulate endogenous cholinergic neurotransmission to stimulate $C$. elegans egg laying through signaling at $\mathrm{nAChRs.} \mathrm{At} \mathrm{this} \mathrm{stage,} \mathrm{the} \mathrm{precise} \mathrm{neurogenetic} \mathrm{mechanism} \mathrm{for} \mathrm{the} \mathrm{effects} \mathrm{of} \mathrm{cocaine}$ on cholinergic neurotransmission remains unclear. Nonetheless, our novel findings demonstrate the utility of the $C$. elegans egg laying circuit as a model system for examination of the cholinergic effects of cocaine and lay the foundation for further mechanistic investigation. 
A conclusive mechanism for regulation of cholinergic neurotransmission by cocaine will require the collection of additional data. To this end, there are several mechanistic investigations that we suggest may shed light on the cholinergic effects of cocaine in future studies.

Cocaine may act on an uncharacterized receptor to regulate cholinergic neurotransmission. A recent biochemical report identified brain acid soluble protein 1 as a novel, pharmacologically relevant receptor for cocaine in mammals (Harraz et al. 2020). Brain acid soluble protein 1 is not conserved in $C$. elegans, but the identification of a novel cocaine receptor illustrates the possibility that cocaine may act on novel, noncanonical targets. Future studies could utilize the genetic tractability of $C$. elegans to identify additional non-canonical cocaine targets that regulate cholinergic neurotransmission via forward genetic screens.

Additionally, cocaine may act simultaneously on one or more amine neurotransmitter systems or receptors to regulate cholinergic neurotransmission. In vivo micro dialysis studies in mammals have shown that by potentiating dopaminergic neurotransmission, cocaine increases $\mathrm{ACh}$ release from the nucleus accumbens and the hippocampus (Imperato et al. 1993; Mark et al. 1999). This raises the possibility that cocaine might act analogously through one or more amine neurotransmitters to regulate ACh release, possibly from the VCs, which are the primary cholinergic motor neurons in the $C$. elegans egg laying circuit or from the HSNs, which have also been reported to function as cholinergic motor neurons (Duerr et al. 2001; Schafer 2006; Pereira et al. 2015). Notably, none of the biogenic amine neurotransmitter mutants tested in the present study besides DAT/dat-1 mutants exhibit a suppressed mean egg laying 
response to cocaine compared to WT. However, because the egg laying circuit expresses multiple functionally redundant receptors for each of the biogenic amine neurotransmitters, it is possible that our genetic analysis of single and double mutants was insufficient to suppress possible amine-dependent egg laying responses to cocaine (Fernandez et al. 2020). Future studies could examine the egg laying behavior of triple and quadruple mutants for the receptors and synthetic enzymes of ACh and each of the amine neurotransmitter systems expressed in the egg laying circuit.

Notably, in a model where the egg laying response to cocaine is dependent on increased ACh signaling, the suppression of the egg laying response to cocaine in ace2; ace-1 double mutants is unexpected. Interestingly, mammals express two distinct types of cholinesterases, a "true" AChE with high substrate specificity for ACh and a less substrate-specific "pseudo" butrylcholinesterase that is the primary metabolic enzyme of cocaine in mammals (Gorelick 1997; Masson and Lockridge 2010). The substrate specificity of AChEs in C. elegans is intermediate to the distinct mammalian AChE and butrylcholinesterase (Johnson and Russell 1983; Kolson and Russell 1985). This raises the possibility that cocaine may be a substrate for $C$. elegans AChEs. Consequently, the suppression of the egg laying response to cocaine in these mutants may indicate that $C$. elegans AChEs metabolize cocaine to a compound which stimulates egg laying through a nicotinic cholinergic pathway. Alternatively, if $C$. elegans AChEs metabolize cocaine, this may inhibit the enzymes' function as ACh-degrading enzymes, causing an increase in ACh levels at nAChRs. The role that the $C$. elegans AChEs play in the mode of action of cocaine is intriguing firstly, because it may be indicative of a possible novel mechanism of cocaine action. Secondly, interest in 
developing recombinant metabolic enzymes of cocaine and its associated metabolites as pharmacotherapeutic interventions for cocaine overdose and cocaine use disorder has accelerated over the last decade (Zheng and Zhan 2008; Zhang et al. 2017).

Additional biochemical and genetic investigation of the effect of cocaine on $C$. elegans AChEs may therefore be a fruitful area of future investigation.

\section{The increase in cocaine-stimulated egg laying in SERT/mod-5 and 5-HT-gated chloride channel/mod-1 null animals may be 5-HT independent}

Our data show that animals with null mutations in SERT/mod-5 and the 5-HTgated chloride channel/mod-1 exhibit an enhanced cocaine-stimulated egg laying response compared to WT animals. These data could be interpreted as aligned with a model in which cocaine increases 5-HT levels, inducing egg laying in WT animals, an effect that is expected to be further potentiated by a lack of 5-HT reuptake in SERT/mod-5 null animals. This serotonergic mechanism is supported by a study that investigated a cocaine-dependent decrease in locomotion speed in $C$. elegans, which is suppressed in 5-HT-gated chloride channel/mod-1, SERT/mod-5, and the 5-HT synthetic enzyme, TPH/tph-1 null mutants (Ward et al. 2009).

However, we show that the null mutant in the 5-HT synthetic enzyme, TPH/tph1(mg280) and the double mutant in the 5-HT receptors, ser-7(tm1325) ser-1(ok345), do not suppress cocaine-stimulated egg laying, pointing to a 5-HT-independent mechanism in cocaine-stimulated egg laying. Additional data in SERT/mod-5 and 5-HT signaling double mutants will be necessary to determine if the enhanced cocaine-stimulated egg laying observed in SERT/mod-5 and 5-HT-gated chloride channel/mod-1 null animals depends on endogenous 5-HT signaling. 
Interestingly, recent reports using calcium imaging of the egg laying circuit in freely behaving worms show evidence of coordination between egg laying behavior, body bend, and locomotion (Zhang et al. 2008; Collins and Koelle 2013; Collins et al. 2016; Kopchock et al. 2021). Such detailed analysis of the coordinated function of both circuits in cocaine-treated WT and mutant animals in vivo will be highly valuable to directly describe the neurobiological mechanism of cocaine action in C. elegans.

Potential of the egg laying circuit as a model system for the cholinergic effects of cocaine

In the present study, we show that, except for a putative null allele of DAT/dat-1, mutants with defects in the amine neurotransmitters DA, Tyr, Oct, and 5-HT do not exhibit a suppressed mean egg laying response to cocaine compared to WT. This is a surprising finding because cocaine's canonical mechanism of action is potentiation of monoaminergic neurotransmission through blockade of monoamine reuptake transporters (Richards and Laurin 2020). We do, however, show that cocaine-stimulated egg laying is suppressed in animals with defects in nicotinic cholinergic neurotransmission, which suggests that cocaine may modulate endogenous ACh signaling to induce egg laying through stimulation of $\mathrm{nAChRs}$ on the vulval muscles. This possibility aligns with previous reports that cocaine increases ACh release in multiple structures in the limbic system (Imperato et al. 1993; Mark et al. 1999). At present, the mechanism underlying potential modulation of cholinergic neurotransmission by cocaine is unclear. Nonetheless, the results of this study provide a background for future investigation utilizing the $C$. elegans egg laying circuit to dissect 
the detailed molecular mechanisms underlying the potential conserved cholinergic effects of cocaine.

\section{Acknowledgments}

This work was supported by NIH Grants DA045364, DA031725, and DA045714. The NIH had no role in the writing of the manuscript or in the decision to submit the manuscript for publication. Some strains were provided by the Caenorhabditis Genetics Center, which is funded by National Institutes of Health Office of Research Infrastructure Programs (P40 OD010440). Some strains were generated by the $C$. elegans Deletion Mutant Consortium. S.E. was supported by the R. Craig and Sheila Yoder Applied Research Fellowship (https://www.davidson.edu/academics/research/undergraduate-research/r-craig-andsheila-yoder-applied-research-fellowship), the Davidson Research Initiative (https://www.davidson.edu/academics/research/undergraduate-research/davidsonresearch-initiative) and the Faculty Study and Research Grant from Davidson College (https://www.davidson.edu/academics/research/faculty-research/faculty-fundingopportunities-research). The authors have declared that no competing interests exist. 


\section{LITERATURE CITED}

Alfonso A, Grundahl K, Duerr JS, Han HP, Rand JB. 1993. The Caenorhabditis elegans unc-17 gene: a putative vesicular acetylcholine transporter. Science. 261(5121):617619. doi:10.1126/science.8342028.

Alkema MJ, Hunter-Ensor M, Ringstad N, Horvitz HR. 2005. Tyramine Functions Independently of Octopamine in the Caenorhabditis elegans Nervous System. Neuron. 46(2):247-260. doi:10.1016/j.neuron.2005.02.024.

Arpagaus M, Combes D, Culetto E, Grauso M, Fedon Y, Romani R, Toutant JP. 1998. Four acetylcholinesterase genes in the nematode Caenorhabditis elegans. J Physiol Paris. 92(5-6):363-367. doi:10.1016/S0928-4257(99)80006-0.

Bany IA, Dong M-Q, Koelle MR. 2003. Genetic and cellular basis for acetylcholine inhibition of Caenorhabditis elegans egg-laying behavior. J Neurosci Off J Soc Neurosci. 23(22):8060-8069.

Cao X, Aballay A. 2016. Neural inhibition of dopaminergic signaling enhances immunity in a cell non-autonomous manner. Curr Biol CB. 26(17):2329-2334. doi:10.1016/j.cub.2016.06.036.

Carnell L, Illi J, Hong SW, McIntire SL. 2005. The G-Protein-Coupled Serotonin Receptor SER-1 Regulates Egg Laying and Male Mating Behaviors in Caenorhabditis elegans. J Neurosci. 25(46):10671-10681. doi:10.1523/JNEUROSCI.3399-05.2005.

Chase D. 2007. Biogenic amine neurotransmitters in C. elegans. WormBook. doi:10.1895/wormbook.1.132.1. [accessed 2020 Apr 15]. http://www.wormbook.org/chapters/www_monoamines/monoamines.html.

Chase DL, Pepper JS, Koelle MR. 2004. Mechanism of extrasynaptic dopamine signaling in Caenorhabditis elegans. Nat Neurosci. 7(10):1096-1103.

doi:10.1038/nn1316.

Churgin MA, McCloskey RJ, Peters E, Fang-Yen C. 2017. Antagonistic Serotonergic and Octopaminergic Neural Circuits Mediate Food-Dependent Locomotory Behavior in Caenorhabditis elegans. J Neurosci. 37(33):7811-7823.

doi:10.1523/JNEUROSCI.2636-16.2017.

Collins KM, Bode A, Fernandez RW, Tanis JE, Brewer JC, Creamer MS, Koelle MR. 2016. Activity of the $C$. elegans egg-laying behavior circuit is controlled by competing activation and feedback inhibition. eLife. doi:10.7554/eLife.21126. [accessed $2020 \mathrm{Jul}$ 9]. https://elifesciences.org/articles/21126.

Collins KM, Koelle MR. 2013. Postsynaptic ERG Potassium Channels Limit Muscle Excitability to Allow Distinct Egg-Laying Behavior States in Caenorhabditis elegans. J Neurosci. 33(2):761-775. doi:10.1523/JNEUROSCI.3896-12.2013. 
Combes D., Fedon Y, Grauso M, Toutant JP, Arpagaus M. 2000. Four genes encode acetylcholinesterases in the nematodes Caenorhabditis elegans and Caenorhabditis briggsae. cDNA sequences, genomic structures, mutations and in vivo expression. J Mol Biol. 300(4):727-742. doi:10.1006/jmbi.2000.3917.

Combes Didier, Fedon Y, Grauso M, Toutant J-P, Arpagaus M. 2000. Four Genes Encode Acetylcholinesterases in the Nematodes Caenorhabditis elegans and Caenorhabditis briggsae. cDNA Sequences, Genomic Structures, Mutations and in vivo Expression. J Mol Biol. 300(4):727-742. doi:10.1006/jmbi.2000.3917.

Combes D, Fedon Y, Toutant JP, Arpagaus M. 2001. Acetylcholinesterase genes in the nematode Caenorhabditis elegans. Int Rev Cytol. 209:207-239. doi:10.1016/s00747696(01)09013-1.

Conradt B, Horvitz HR. 1998. The C. elegans Protein EGL-1 Is Required for Programmed Cell Death and Interacts with the Bcl-2-like Protein CED-9. Cell. 93(4):519-529. doi:10.1016/S0092-8674(00)81182-4.

Culotti JG, Von Ehrenstein G, Culotti MR, Russell RL. 1981. A Second Class of Acetylcholinesterase-Deficient Mutants of the Nematode CAENORHABDITIS ELEGANS. Genetics. 97(2):281-305.

Czoty PW, Stoops WW, Rush CR. 2016. Evaluation of the "Pipeline" for Development of Medications for Cocaine Use Disorder: A Review of Translational Preclinical, Human Laboratory, and Clinical Trial Research. Pharmacol Rev. 68(3):533-562. doi:10.1124/pr.115.011668.

Dempsey CM, Mackenzie SM, Gargus A, Blanco G, Sze JY. 2005. Serotonin (5HT), Fluoxetine, Imipramine and Dopamine Target Distinct 5HT Receptor Signaling to Modulate Caenorhabditis elegans Egg-Laying Behavior. Genetics. 169(3):1425-1436. doi:10.1534/genetics.104.032540.

Desai C, Horvitz HR. 1989. Caenorhabditis elegans mutants defective in the functioning of the motor neurons responsible for egg laying. Genetics. 121(4):703-721.

Duerr JS, Gaskin J, Rand JB. 2001. Identified neurons in C. elegans coexpress vesicular transporters for acetylcholine and monoamines. Am J Physiol Cell Physiol. 280(6):C1616-1622. doi:10.1152/ajpcell.2001.280.6.C1616.

Dvir H, Silman I, Harel M, Rosenberry TL, Sussman JL. 2010. Acetylcholinesterase: From 3D Structure to Function. Chem Biol Interact. 187(1-3):10-22. doi:10.1016/j.cbi.2010.01.042.

Engleman EA, Katner SN, Neal-Beliveau BS. 2016. Caenorhabditis elegans as a Model to Study the Molecular and Genetic Mechanisms of Drug Addiction. Prog Mol Biol Transl Sci. 137:229-252. doi:10.1016/bs.pmbts.2015.10.019. 
Engleman EA, Steagall KBI, Bredhold KE, Breach M, Kline HL, Bell RL, Katner SN, Neal-Beliveau BS. 2018. Caenorhabditis elegans Show Preference for Stimulants and Potential as a Model Organism for Medications Screening. Front Physiol. 9. doi:10.3389/fphys.2018.01200. [accessed 2019 Sep 2]. https://www.frontiersin.org/articles/10.3389/fphys.2018.01200/full.

Fernandez RW, Wei K, Wang EY, Mikalauskaite D, Olson A, Pepper J, Christie N, Kim S, Weissenborn S, Sarov M, et al. 2020. Cellular Expression and Functional Roles of All 26 Neurotransmitter GPCRs in the C. elegans Egg-Laying Circuit. J Neurosci Off J Soc Neurosci. 40(39):7475-7488. doi:10.1523/JNEUROSCI.1357-20.2020.

Fleming JT, Squire MD, Barnes TM, Tornoe C, Matsuda K, Ahnn J, Fire A, Sulston JE, Barnard EA, Sattelle DB, et al. 1997. Caenorhabditis elegans Levamisole Resistance Geneslev-1, unc-29, and unc-38 Encode Functional Nicotinic Acetylcholine Receptor Subunits. J Neurosci. 17(15):5843-5857. doi:10.1523/JNEUROSCI.17-15-05843.1997.

Gorelick DA. 1997. Enhancing cocaine metabolism with butyrylcholinesterase as a treatment strategy. Drug Alcohol Depend. 48(3):159-165. doi:10.1016/s03768716(97)00119-1.

Gottschling D-C, Döring F, Lüersen K. 2017. Locomotion Behavior Is Affected by the GaS Pathway and the Two-Pore-Domain K+ Channel TWK-7 Interacting in GABAergic Motor Neurons in Caenorhabditis elegans. Genetics. 206(1):283-297. doi:10.1534/genetics.116.195669.

Hapiak VM, Hobson RJ, Hughes L, Smith K, Harris G, Condon C, Komuniecki P, Komuniecki RW. 2009. Dual Excitatory and Inhibitory Serotonergic Inputs Modulate Egg Laying in Caenorhabditis elegans. Genetics. 181(1):153-163.

doi:10.1534/genetics.108.096891.

Hare EE, Loer CM. 2004. Function and evolution of the serotonin-synthetic bas-1 gene and other aromatic amino acid decarboxylase genes in Caenorhabditis. BMC Evol Biol. 4:24. doi:10.1186/1471-2148-4-24.

Harraz MM, Malla AP, Semenza ER, Shishikura M, Hwang Y, Kang IG, Song YJ, Snowman AM, Cortes P, Snyder SH. 2020. Cocaine receptor identified as BASP1. bioRxiv.:2020.11.23.392787. doi:10.1101/2020.11.23.392787.

Hart A. 2006. Behavior. WormBook. doi:10.1895/wormbook.1.87.1. [accessed 2020 Oct 19]. http://www.wormbook.org/chapters/www_behavior/behavior.html.

Hasselmo ME. 2006. The Role of Acetylcholine in Learning and Memory. Curr Opin Neurobiol. 16(6):710-715. doi:10.1016/j.conb.2006.09.002.

Hedegaard H, Spencer MR, Garnett M. 2020. Increase in Drug Overdose Deaths Involving Cocaine: United States, 2009-2018. (384):8. 
Higgins GA, Fletcher PJ. 2003. Serotonin and drug reward: focus on 5-HT2C receptors. Eur J Pharmacol. 480(1-3):151-162. doi:10.1016/j.ejphar.2003.08.102.

Hobson RJ, Hapiak VM, Xiao H, Buehrer KL, Komuniecki PR, Komuniecki RW. 2006. SER-7, a Caenorhabditis elegans 5-HT7-like Receptor, Is Essential for the 5-HT Stimulation of Pharyngeal Pumping and Egg Laying. Genetics. 172(1):159-169. doi:10.1534/genetics.105.044495.

Horvitz HR, Chalfie M, Trent C, Sulston JE, Evans PD. 1982. Serotonin and octopamine in the nematode Caenorhabditis elegans. Science. 216(4549):1012-1014. doi:10.1126/science.6805073.

Imperato A, Obinu MC, Gessa GL. 1993. Effects of cocaine and amphetamine on acetylcholine release in the hippocampus and caudate nucleus. Eur J Pharmacol. 238(2):377-381. doi:10.1016/0014-2999(93)90869-J.

Jayanthi LD, Apparsundaram S, Malone MD, Ward E, Miller DM, Eppler M, Blakely RD. 1998. The Caenorhabditis elegans gene T23G5.5 encodes an antidepressant- and cocaine-sensitive dopamine transporter. Mol Pharmacol. 54(4):601-609.

Johnson CD, Russell RL. 1983. Multiple Molecular Forms of Acetylcholinesterase in the Nematode Caenorhabditis elegans. J Neurochem. 41(1):30-46. doi:10.1111/j.14714159.1983.tb11811.x.

Kampman KM. 2019. The treatment of cocaine use disorder. Sci Adv. 5(10). doi:10.1126/sciadv.aax1532. [accessed 2020 Sep 1]. https://www.ncbi.nIm.nih.gov/pmc/articles/PMC6795516/.

Kim J, Poole DS, Waggoner LE, Kempf A, Ramirez DS, Treschow PA, Schafer WR. 2001. Genes affecting the activity of nicotinic receptors involved in Caenorhabditis elegans egg-laying behavior. Genetics. 157(4):1599-1610.

Klinkenberg I, Sambeth A, Blokland A. 2011. Acetylcholine and attention. Behav Brain Res. 221(2):430-442. doi:10.1016/j.bbr.2010.11.033.

Kolson DL, Russell RL. 1985. A novel class of acetylcholinesterase, revealed by mutations, in the nematode Caenorhabditis elegans. J Neurogenet. 2(2):93-110. doi:10.3109/01677068509100145.

Kopchock RJ, Ravi B, Bode A, Collins KM. 2021. The sex-specific VC neurons are mechanically activated motor neurons that facilitate serotonin-induced egg laying in $\mathrm{C}$. elegans. J Neurosci. doi:10.1523/JNEUROSCl.2150-20.2021. [accessed 2021 Mar 27]. https://www.jneurosci.org/content/early/2021/03/11/JNEUROSCI.2150-20.2021.

Lackner MR, Nurrish SJ, Kaplan JM. 1999. Facilitation of Synaptic Transmission by EGL-30 Gqa and EGL-8 PLCB: DAG Binding to UNC-13 Is Required to Stimulate Acetylcholine Release. Neuron. 24(2):335-346. doi:10.1016/S0896-6273(00)80848-X. 
Lints R, Emmons SW. 1999. Patterning of dopaminergic neurotransmitter identity among Caenorhabditis elegans ray sensory neurons by a TGFbeta family signaling pathway and a Hox gene. Dev Camb Engl. 126(24):5819-5831.

Lipari RN, Van Horn SL. 2013. Trends in Substance Use Disorders Among Adults Aged 18 or Older. In: The CBHSQ Report. Rockville (MD): Substance Abuse and Mental Health Services Administration (US). [accessed 2020 Sep 1]. http://www.ncbi.nlm.nih.gov/books/NBK447253/.

Liu Y, LeBoeuf B, Garcia LR. 2007. Gaq-Coupled Muscarinic Acetylcholine Receptors Enhance Nicotinic Acetylcholine Receptor Signaling in Caenorhabditis elegans Mating Behavior. J Neurosci. 27(6):1411-1421. doi:10.1523/JNEUROSCI.4320-06.2007.

Mark GP, Hajnal A, Kinney AE, Keys AS. 1999. Self-administration of cocaine increases the release of acetylcholine to a greater extent than response-independent cocaine in the nucleus accumbens of rats. Psychopharmacology (Berl). 143(1):47-53.

doi:10.1007/s002130050918.

Masson P, Lockridge O. 2010. Butyrylcholinesterase for protection from organophosphorus poisons; catalytic complexities and hysteretic behavior. Arch Biochem Biophys. 494(2):107. doi:10.1016/j.abb.2009.12.005.

McDonald PW, Hardie SL, Jessen TN, Carvelli L, Matthies DS, Blakely RD. 2007. Vigorous Motor Activity in Caenorhabditis elegans Requires Efficient Clearance of Dopamine Mediated by Synaptic Localization of the Dopamine Transporter DAT-1. J Neurosci. 27(51):14216-14227. doi:10.1523/JNEUROSCI.2992-07.2007.

Müller CP, Carey RJ, Huston JP, De Souza Silva MA. 2007. Serotonin and psychostimulant addiction: focus on 5-HT1A-receptors. Prog Neurobiol. 81(3):133-178. doi:10.1016/j.pneurobio.2007.01.001.

Nestler EJ. 2005. The neurobiology of cocaine addiction. Sci Pract Perspect. 3(1):4-10.

Olde B, McCombie WR. 1997. Molecular cloning and functional expression of a serotonin receptor fromCaenorhabditis elegans. J Mol Neurosci. 8(1):53-62. doi:10.1007/BF02736863.

Pereira L, Kratsios P, Serrano-Saiz E, Sheftel H, Mayo AE, Hall DH, White JG, LeBoeuf B, Garcia LR, Alon U, et al. 2015. A cellular and regulatory map of the cholinergic nervous system of C. elegans. Shen K, editor. eLife. 4:e12432.

doi:10.7554/elife.12432.

Pitts DK, Marwah J. 1989. Autonomic actions of cocaine. Can J Physiol Pharmacol. 67(9):1168-1176. doi:10.1139/y89-186.

Rand J. 2007. Acetylcholine. WormBook. doi:10.1895/wormbook.1.131.1. [accessed 2020 Apr 15]. http://www.wormbook.org/chapters/www_acetylcholine/acetylcholine.html. 
Rand JB, Russell RL. 1984. Choline acetyltransferase-deficient mutants of the nematode Caenorhabditis elegans. Genetics. 106(2):227-248.

Rand JB, Russell RL. 1985. Properties and Partial Purification of Choline Acetyltransferase from the Nematode Caenorhabditis elegans. J Neurochem. 44(1):189-200. doi:10.1111/j.1471-4159.1985.tb07130.x.

Ranganathan R, Cannon SC, Horvitz HR. 2000. MOD-1 is a serotonin-gated chloride channel that modulates locomotory behaviour in C. elegans. Nature. 408(6811):470475. doi:10.1038/35044083.

Ranganathan R, Sawin ER, Trent C, Horvitz HR. 2001. Mutations in the Caenorhabditis elegans serotonin reuptake transporter MOD-5 reveal serotonin-dependent and independent activities of fluoxetine. J Neurosci Off J Soc Neurosci. 21(16):5871-5884.

Richards JR, Laurin EG. 2020. Cocaine. In: StatPearls. Treasure Island (FL): StatPearls Publishing. [accessed 2020 Jun 24]. http://www.ncbi.nlm.nih.gov/books/NBK430769/.

Richmond JE, Jorgensen EM. 1999. One GABA and two acetylcholine receptors function at the C. elegans neuromuscular junction. Nat Neurosci. 2(9):791-797. doi: $10.1038 / 12160$.

Schafer W. 2005. Egg-laying. WormBook. doi:10.1895/wormbook.1.38.1. [accessed 2019 Aug 19]. http://www.wormbook.org/chapters/www_egglaying/egglaying.html.

Schafer WR. 2006. Genetics of Egg-Laying in Worms. Annu Rev Genet. 40(1):487-509. doi:10.1146/annurev.genet.40.110405.090527.

Schafer WR, Kenyon CJ. 1995. A calcium-channel homologue required for adaptation to dopamine and serotonin in Caenorhabditis elegans. Nature. 375(6526):73-78. doi:10.1038/375073a0.

Sofuoglu M, Mooney M. 2009. Cholinergic Functioning in Stimulant Addiction: Implications for Medications Development. CNS Drugs. 23(11):939-952. doi:10.2165/11310920-000000000-00000.

Stiernagle T. 2006. Maintenance of C. elegans. WormBook. doi:10.1895/wormbook.1.101.1. [accessed 2020 Jul 30]. http://www.wormbook.org/chapters/www_strainmaintain/strainmaintain.html.

Sze JY, Victor M, Loer C, Shi Y, Ruvkun G. 2000. Food and metabolic signalling defects in a Caenorhabditis elegans serotonin-synthesis mutant. Nature. 403(6769):560-564. doi:10.1038/35000609.

The C. elegans Deletion Mutant Consortium. 2012. Large-Scale Screening for Targeted Knockouts in the Caenorhabditis elegans Genome. G3 GenesGenomesGenetics. 2(11):1415-1425. doi:10.1534/g3.112.003830. 
Trent C, Tsuing N, Horvitz HR. 1983. Egg-laying defective mutants of the nematode Caenorhabditis elegans. Genetics. 104(4):619-647.

Ward A, Walker VJ, Feng Z, Xu XZS. 2009. Cocaine Modulates Locomotion Behavior in C. elegans. PLOS ONE. 4(6):e5946. doi:10.1371/journal.pone.0005946.

Weinshenker D, Garriga G, Thomas JH. 1995. Genetic and pharmacological analysis of neurotransmitters controlling egg laying in C. elegans. J Neurosci. 15(10):6975-6985. doi:10.1523/JNEUROSCI.15-10-06975.1995.

White JG, Southgate E, Thomson JN, Brenner S. 1986. The structure of the nervous system of the nematode Caenorhabditis elegans. Philos Trans R Soc Lond B Biol Sci. 314(1165):1-340. doi:10.1098/rstb.1986.0056.

Zhang M, Chung SH, Fang-Yen C, Craig C, Kerr RA, Suzuki H, Samuel ADT, Mazur E, Schafer WR. 2008. A self-regulating feed-forward circuit controlling C. elegans egglaying behavior. Curr Biol CB. 18(19):1445-1455. doi:10.1016/j.cub.2008.08.047.

Zhang T, Zheng X, Zhou Z, Chen X, Jin Z, Deng J, Zhan C-G, Zheng F. 2017. Clinical Potential of an Enzyme-based Novel Therapy for Cocaine Overdose. Sci Rep. 7(1):1-9. doi:10.1038/s41598-017-14105-5.

Zheng F, Zhan C-G. 2008. Rational design of an enzyme mutant for anti-cocaine therapeutics. J Comput Aided Mol Des. 22(9):661-671. doi:10.1007/s10822-007-91449. 

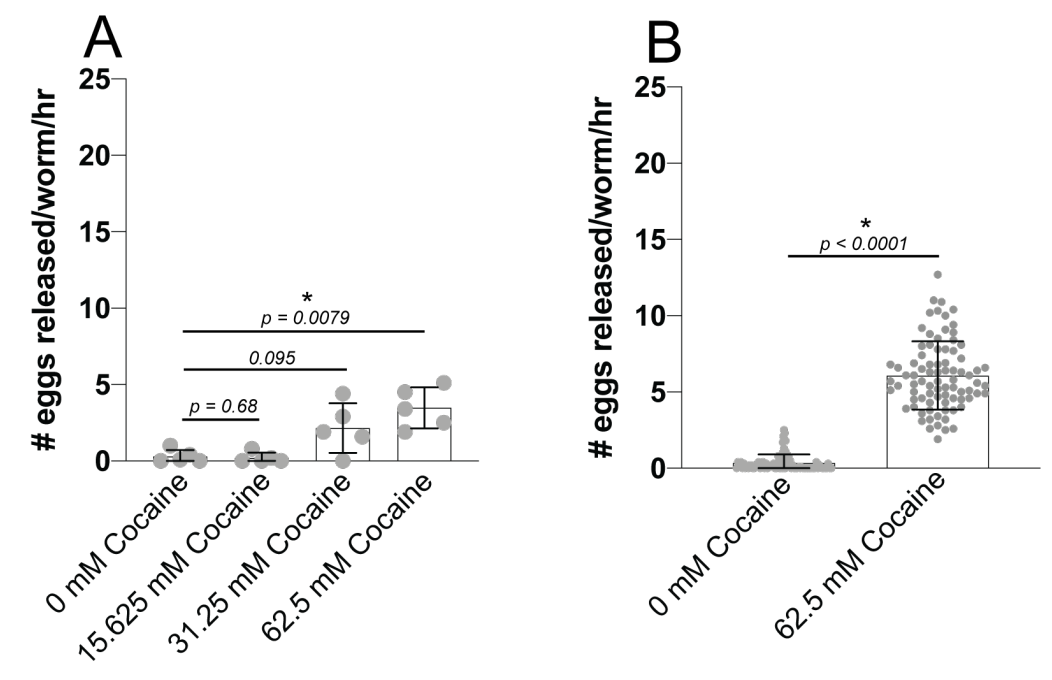

Fig 1: Cocaine stimulates $C$. elegans egg laying behavior. A. Egg laying response of $C$. elegans to a series of increasing concentrations of cocaine in liquid media. B. Egg laying response of $C$. elegans to $62.5 \mathrm{mM}$ cocaine in liquid media compared to $62.5 \mathrm{mM}$ sucrose control. For the data shown in A we performed five independent experiments with 10 animals in each group. The data shown in panel $B$ show a compiled experiment for wild type worms from our experiments (83 independent experiments with 10 animals in each group). Error bars represent SD. Mann-Whitney U-test. Significance indicated by asterisks. 


\section{A}
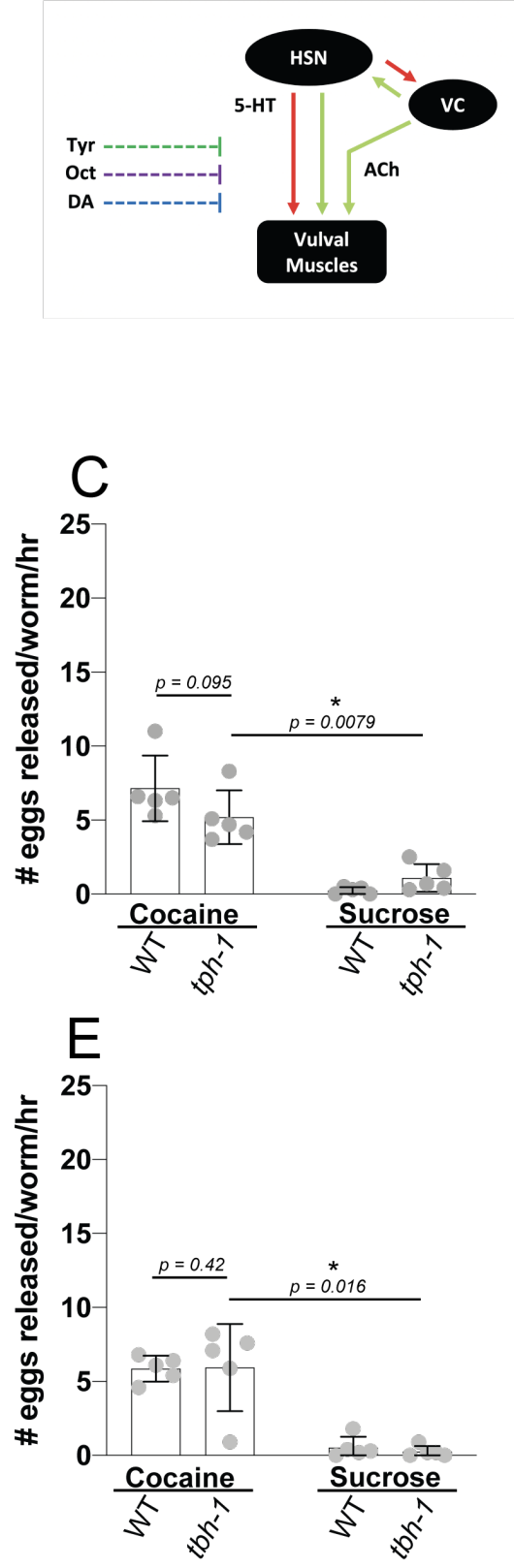
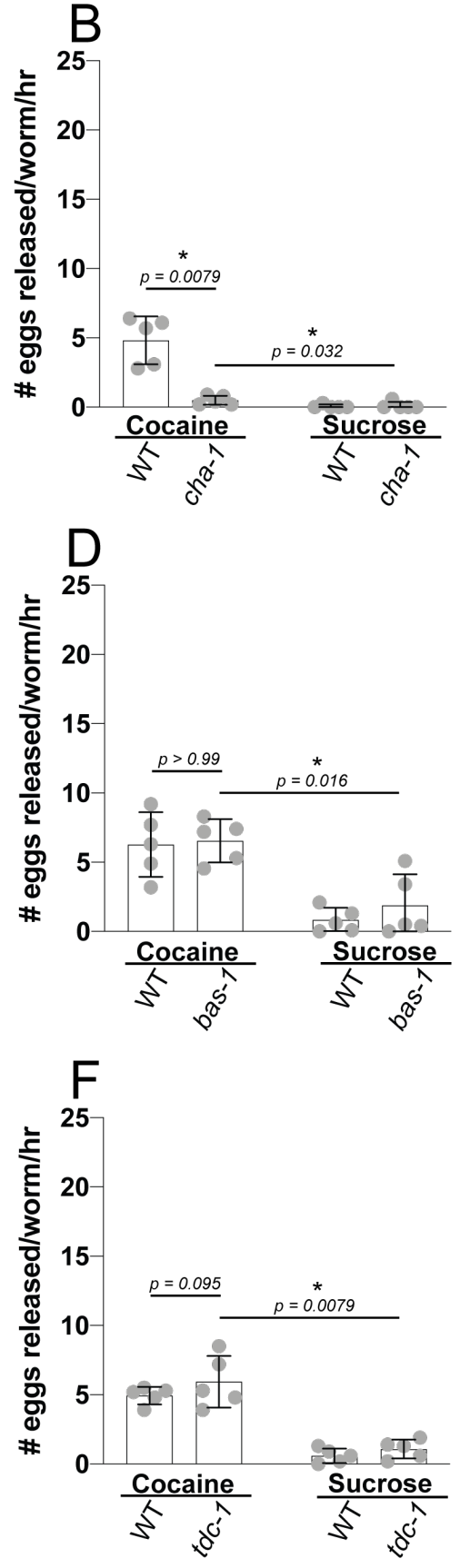

Fig 2: ChAT is required for the egg laying response to cocaine. A. Schematic of the C. elegans egg laying circuit showing HSNs, VCs, the vulval muscles, and the neurotransmitter systems expressed in the egg laying circuit, which include Tyr (dark green), Oct (purple), DA (blue), 5-HT (red), and ACh (light green). Extrasynaptic neurotransmitter systems marked with dashed lines. Synaptic neurotransmitter systems marked with solid lines. Egg laying behavior of mutants for B. ChAT/(cha-1(p1152), C. TPH/tph-1(mg280), D. AADC/bas-1(ad446), E. TDC/tdc-1(n3419), and F. TBH/tbh1 (n3247) in $62.5 \mathrm{mM}$ cocaine or a $62.5 \mathrm{mM}$ sucrose control compared to WT. We 
bioRxiv preprint doi: https://doi.org/10.1101/2020.11.24.396333; this version posted April 2, 2021. The copyright holder for this preprint (which was not certified by peer review) is the author/funder, who has granted bioRxiv a license to display the preprint in perpetuity. It is made available under aCC-BY-NC-ND 4.0 International license.

performed five independent experiments with 10 animals in each group. Error bars represent SD. Mann-Whitney U-test. Significance indicated by asterisks. 

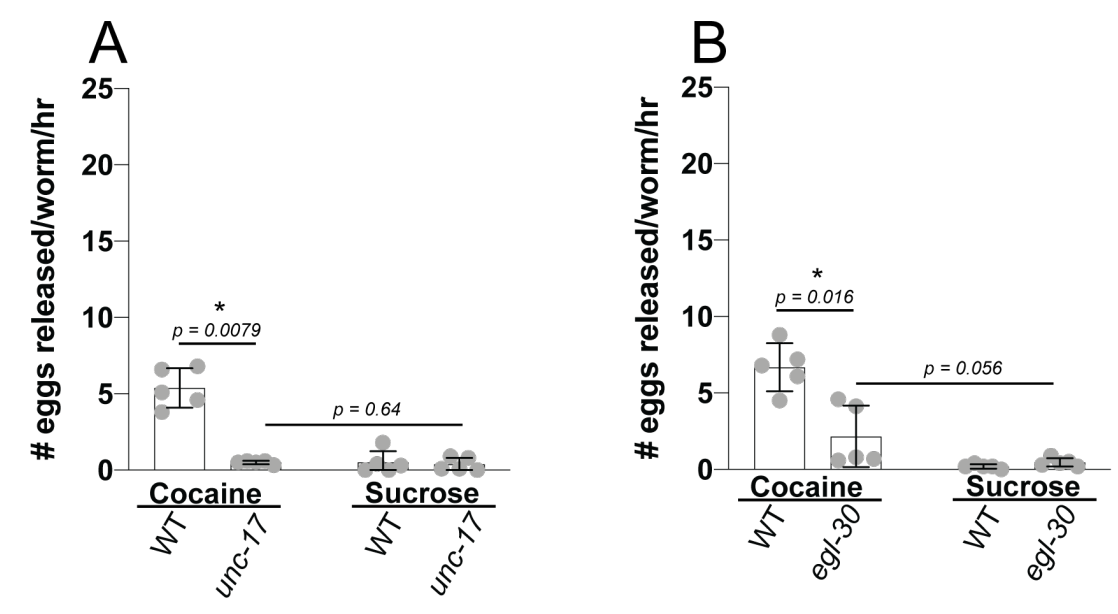

Fig 3: VAChT and $\mathrm{Ga}_{q}$ are required for the egg laying response to cocaine. Egg laying behavior of mutants for A. VAChT/unc-17(e245) and B. Ga egl-30(ad806), which are required for $\mathrm{ACh}$ release from motor neurons, in $62.5 \mathrm{mM}$ cocaine or a $62.5 \mathrm{mM}$ sucrose control compared to WT. We performed five independent experiments with 10 animals in each group. Error bars represent SD. Mann-Whitney U-test. Significance indicated by asterisks. 

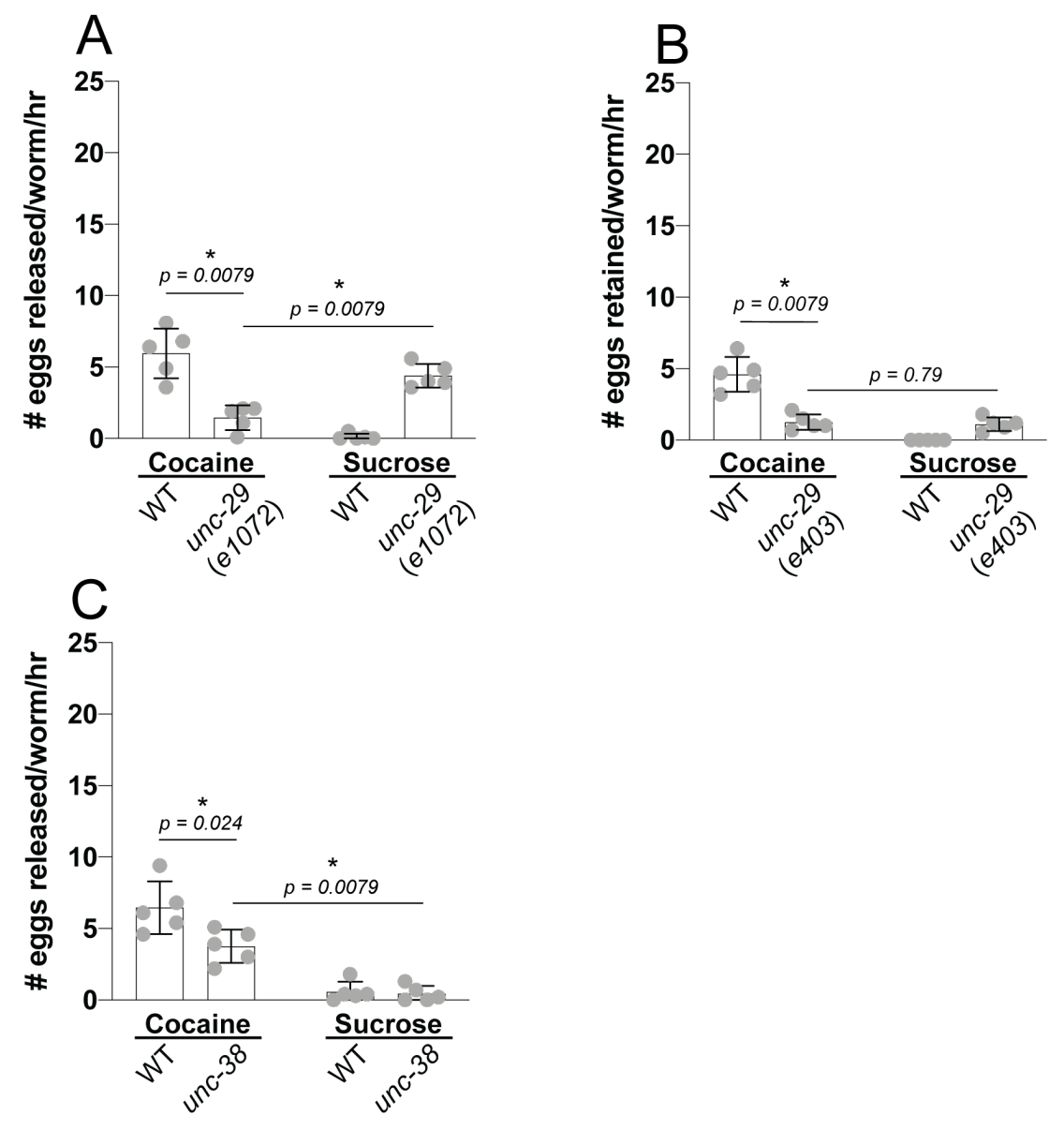

Fig 4: $n A C h R s$ are required for the egg laying response to cocaine. Egg laying behavior of A. CHRNB/unc-29(e1072), B. CHRNB/unc-29(e403), and C. CHRNA/unc$38(e 264)$ in $62.5 \mathrm{mM}$ cocaine or a $62.5 \mathrm{mM}$ sucrose control compared to WT. We performed five independent experiments with 10 animals in each group. Error bars represent SD. Mann-Whitney U-test. Significance indicated by asterisks. 

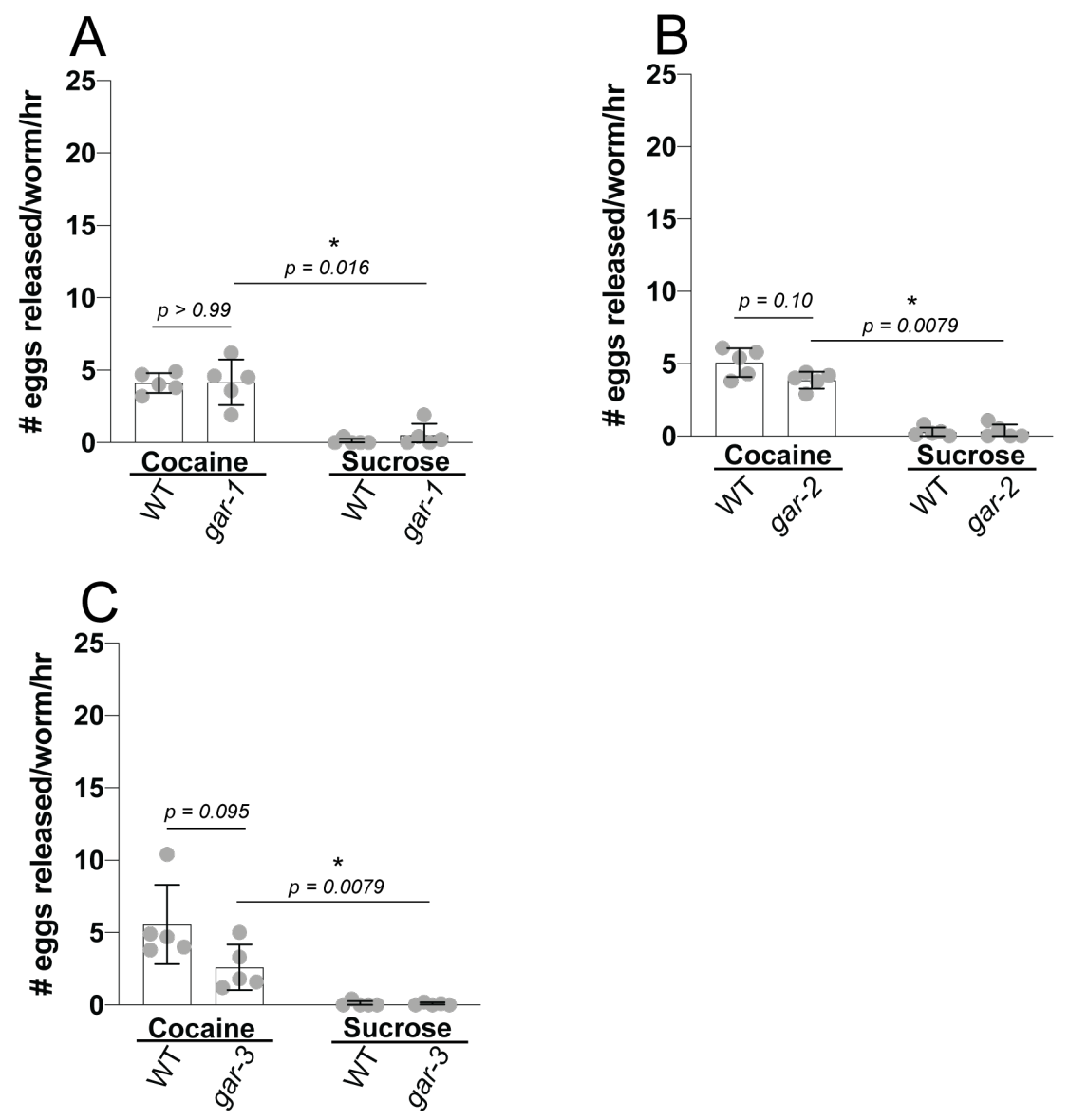

Fig 5: $m A C h R s$ are not required for the egg laying response to cocaine. Egg laying behavior of A. gar-1(ok755), B. gar-2(ok520), and C. gar-3(gk305) in $62.5 \mathrm{mM}$ cocaine or a $62.5 \mathrm{mM}$ sucrose control compared to WT. We performed five independent experiments with 10 animals in each group. Error bars represent SD. Mann-Whitney Utest. Significance indicated by asterisks. 

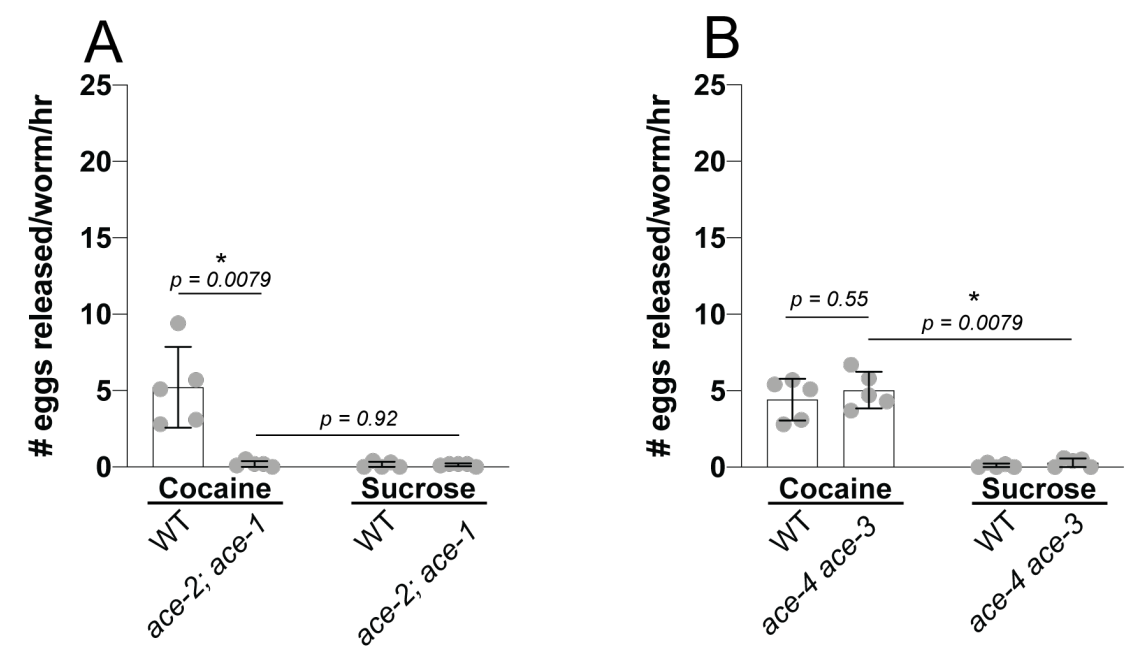

Fig 6: AChE-encoding genes are required for the egg laying response to cocaine. Egg laying behavior of A. ace-2(g72); ace-1(p1000) and B. ace-4 ace-3(dc2) in 62.5 $\mathrm{mM}$ cocaine or a $62.5 \mathrm{mM}$ sucrose control compared to WT. We performed five independent experiments with 10 animals in each group. Error bars represent SD. Mann-Whitney U-test. Significance indicated by asterisks. 

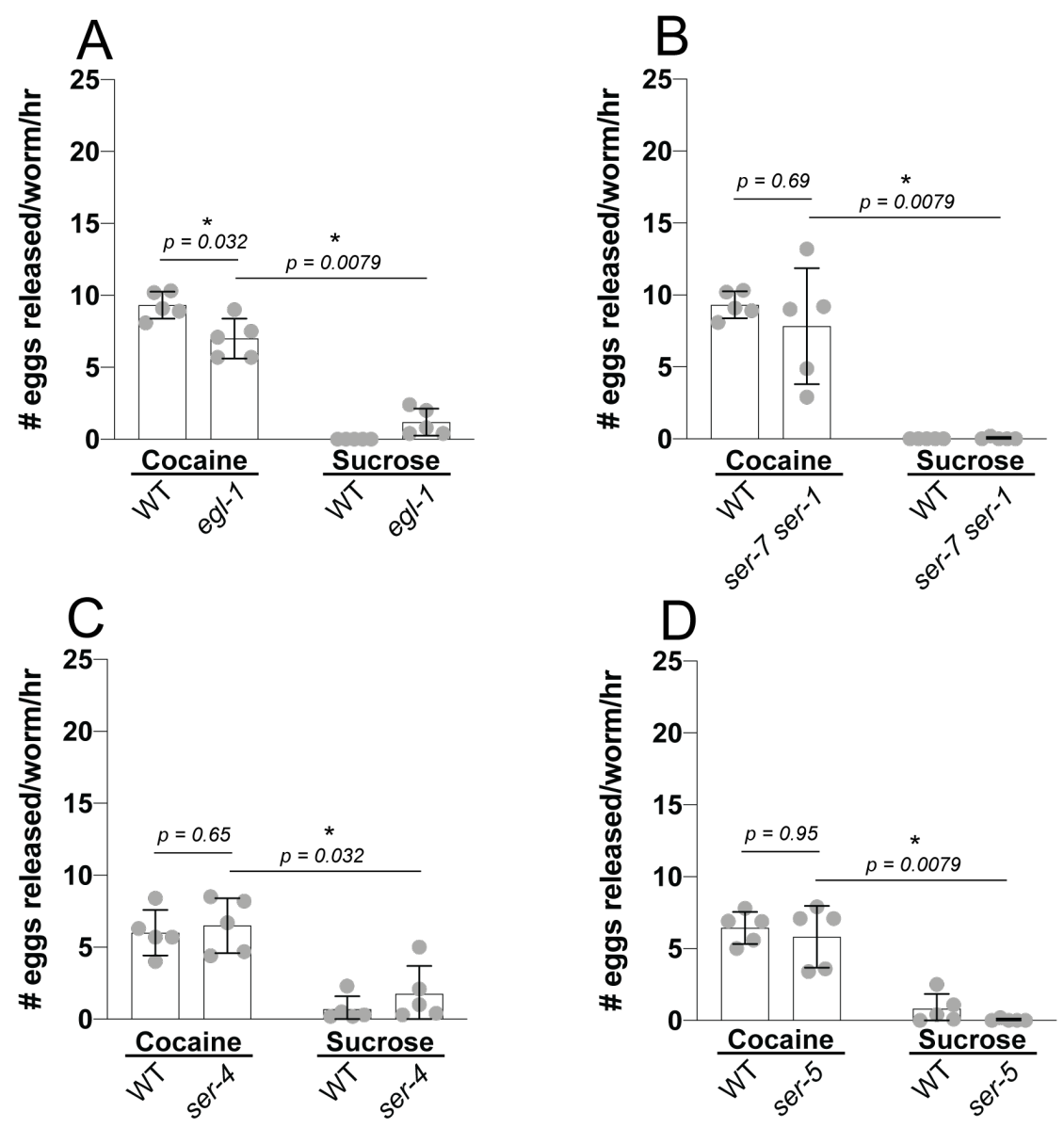

Fig 7: The HSNs, but not 5-HT receptors, are required for the egg laying response to cocaine. Egg laying behavior of A. animals lacking HSNs/egl-1(n487), B. ser7(tm1325) ser-1(ok345) double mutants, C. ser-4(ok512) mutants, and D. ser-5(ok3087) mutants in $62.5 \mathrm{mM}$ cocaine or a $62.5 \mathrm{mM}$ sucrose control compared to WT. We performed five independent experiments with 10 animals in each group. Error bars represent SD. Mann-Whitney U-test. Significance indicated by asterisks. 

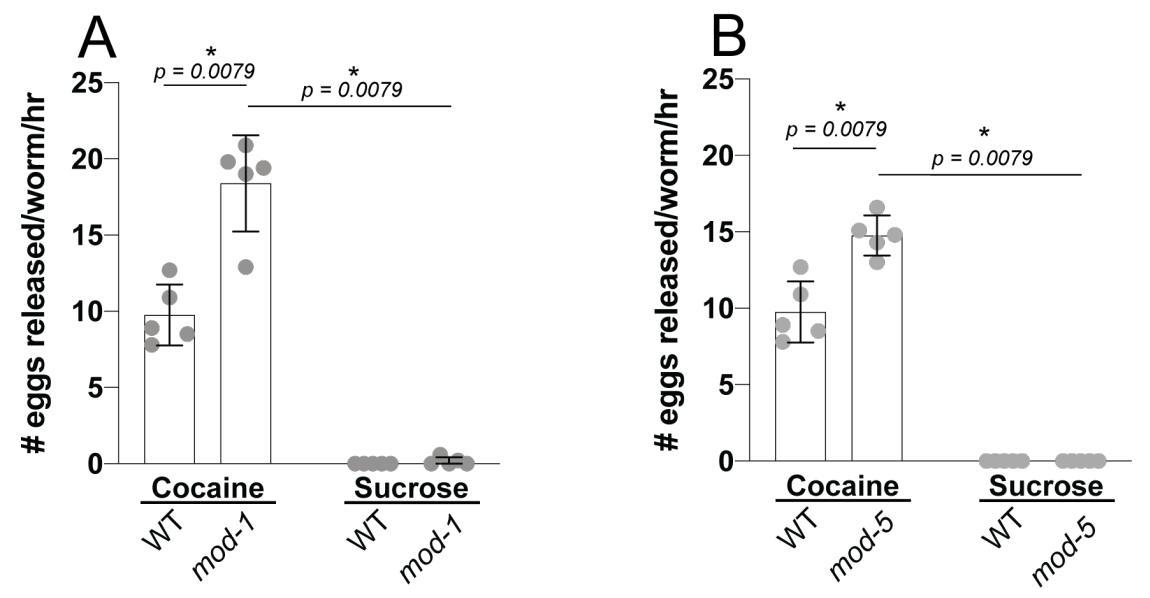

Fig 8: The mean egg laying response to cocaine is increased in 5-HT-gated chloride channel mutants and SERT mutants. A. 5-HT-gated chloride channel/mod1(ok103) mutants, B. SERT/mod-5(n3314) mutants in $62.5 \mathrm{mM}$ cocaine or a $62.5 \mathrm{mM}$ sucrose control compared to WT. We performed five independent experiments with 10 animals in each group. Error bars represent SD. Mann-Whitney U-test. Significance indicated by asterisks. 

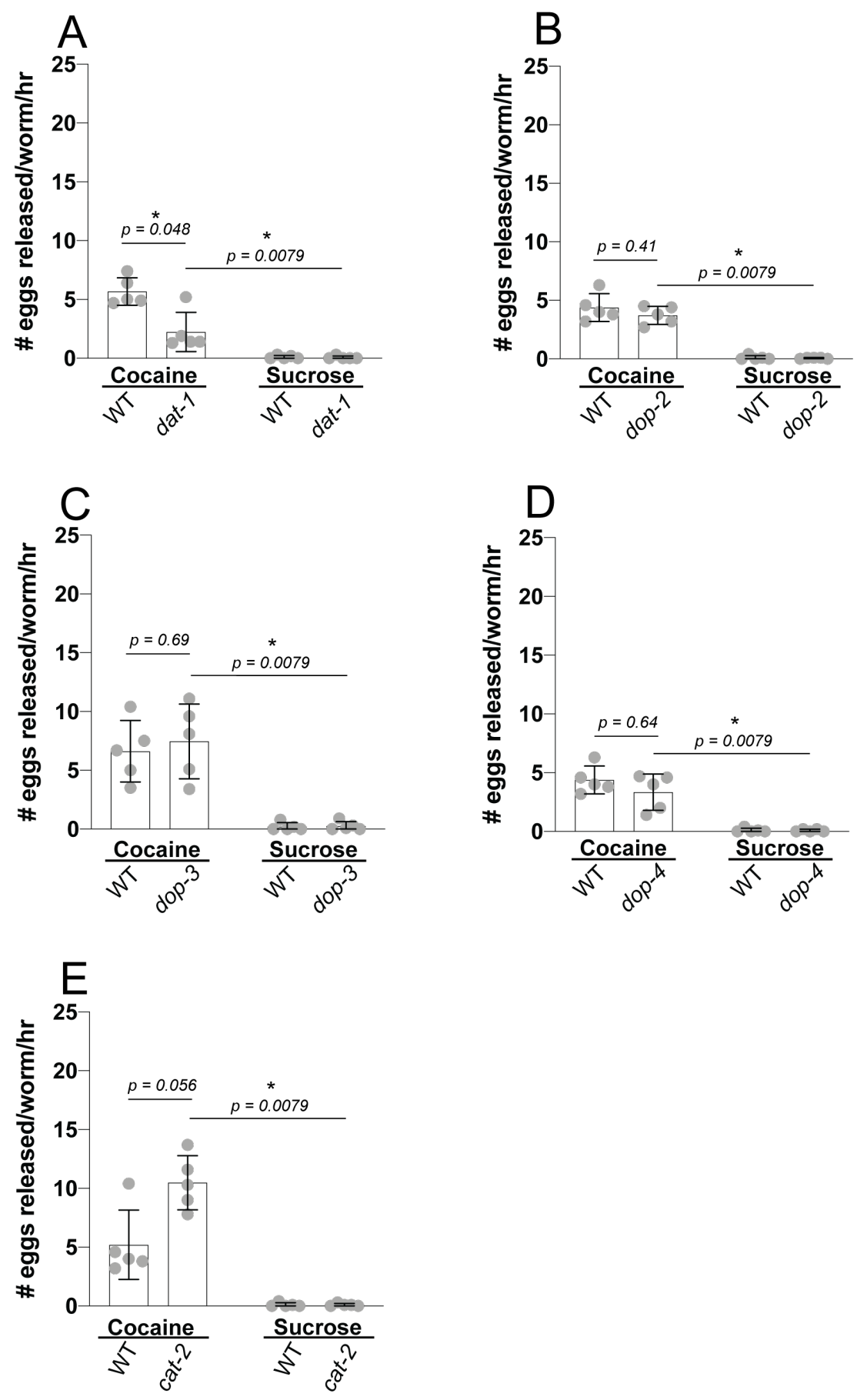

Fig 9: DAT is required for the egg laying response to cocaine, but not other DA signaling genes. Egg laying behavior of A. DAT mutants dat-1(ok157), B. dop2(vs105), C. dop-3(vs106), D. dop-4(ok1321), and E. cat-2(e1112) in $62.5 \mathrm{mM}$ cocaine or a $62.5 \mathrm{mM}$ sucrose control compared to WT. We performed five independent 
bioRxiv preprint doi: https://doi.org/10.1101/2020.11.24.396333; this version posted April 2, 2021. The copyright holder for this preprint (which was not certified by peer review) is the author/funder, who has granted bioRxiv a license to display the preprint in perpetuity. It is made available under aCC-BY-NC-ND 4.0 International license.

experiments with 10 animals in each group. Error bars represent SD. Mann-Whitney Utest. Significance indicated by asterisks. 

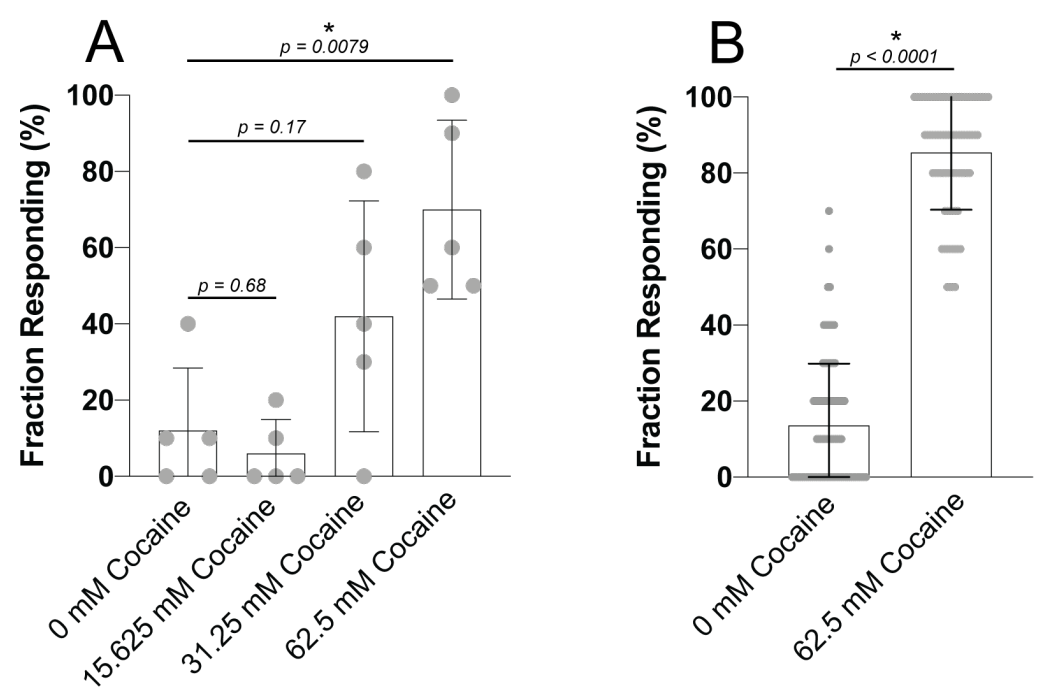

Fig 10: Fraction of WT C. elegans that emit an egg laying response to cocaine treatment. Fraction responding, defined as the fraction of animals releasing one or more eggs, of A. WT C. elegans to a series of increasing concentrations of cocaine in liquid media and B. WT C. elegans to $62.5 \mathrm{mM}$ cocaine in liquid media compared to $62.5 \mathrm{mM}$ sucrose control. For the data shown in A we performed five independent experiments with 10 animals in each group. For the data shown in panel $\mathrm{B}$ we reanalyzed 83 independent experiments with 10 animals in each group for which we had previously reported the mean number of eggs laid in $1 \mathrm{hr}$. Error bars represent SD. Mann-Whitney U-test. Significance indicated by asterisks. 